\title{
No Correlation between the Month of Birth and the Likelihood of Developing Inflammatory Bowel Disease Later in Life
}

\author{
E. M. De Boer', M. A. Brink², M. H. M. G. Houben ${ }^{3}$, A. H. A. M. van Oijen', W. A. De Boer ${ }^{*}$ \\ ${ }^{1}$ Leids Universitair Medisch Centrum, Leiden, The Netherlands \\ ${ }^{2}$ Meander Medisch Centrum, Amersfoort, The Netherlands \\ ${ }^{3}$ Haga Teaching Hospital, The Hague, The Netherlands \\ ${ }^{4}$ Medisch Centrum Alkmaar, Alkmaar, The Netherlands \\ ${ }^{5}$ Bernhoven Ziekenhuis, Uden, The Netherlands \\ Email: *w.deboer@bernhoven.nl
}

Received 6 March 2014; revised 8 April 2014; accepted 16 April 2014

Copyright (C) 2014 by authors and Scientific Research Publishing Inc.

This work is licensed under the Creative Commons Attribution International License (CC BY).

http://creativecommons.org/licenses/by/4.0/

(c) (i) Open Access

\begin{abstract}
Background: The etiology of Crohn's disease (CD) and Ulcerative Colitis (UC) remains unclear. It has been suggested that apart from genetic factors, prenatal or perinatal environmental factors could change the risk of developing inflammatory bowel disease (IBD) later in life. Seasonality in birth distribution over the year has been demonstrated for several immune diseases, but studies on IBD have had inconsistent results. Aim: The aim of this study was to investigate in the Netherlands the effect of the month of birth on the probability to develop IBD later in life. Methods: Birth data from CD patients and UC patients of 4 different Dutch hospitals were compared to a control group of irritable bowel syndrome (IBS) patients from the same hospitals. A chi-square test was used to test whether there was heterogeneity between the monthly and seasonal birth rates of the three groups. Results: The patient cohort consisted of 1183 CD patients and 1293 UC patients. The control group consisted of 2113 IBS patients. Data showed no difference in birth distribution over the year or over the four seasons of IBD patients as compared to the control group. P-values over the year and over the seasons respectively are 0.428 and 0.237 for CD and 0.311 and 0.812 for UC. Conclusions: There is no seasonality in the distribution of births of IBD patients as compared to controls. The hypothesis that environmental factors present at the time of birth play a role in the pathogenesis of IBD is not supported by these data.
\end{abstract}

\section{Keywords}

Inflammatory Bowel Disease; Season; Seasonality; Month; Birth; Crohn Disease; Colitis Ulcerative

\footnotetext{
${ }^{*}$ Corresponding author.
}

How to cite this paper: De Boer, E.M., et al. (2014) No Correlation between the Month of Birth and the Likelihood of Developing Inflammatory Bowel Disease Later in Life. Open Journal of Gastroenterology, 4, 192-197. 


\section{Introduction}

IBD is characterized by chronic, recurrent inflammation of the Gastro Intestinal (GI) tract. CD can affect any component of the gastro-intestinal tract, although it mostly affects the terminal ileum, whereas UC is strictly limited to the colon. CD and UC have distinct pathologic and clinical characteristics, however the precise etiology and pathogenesis for both diseases are still unclear [1].

It has been suggested that, next to genetics, prenatal or perinatal environmental factors could change the risk of developing inflammatory bowel disease later in life [2].

The immune system of a newborn baby is shaped and conditioned by the exposure to antigens from its environment. It is conceivable that these earliest contacts between the innate immune system and the viruses and bacteria that it encounters can shape the immune system in a certain direction. It is also conceivable that a baby born in the winter is primarily exposed to a different set of infections, or antigens as compared to a baby born in the summer. In this way these earliest antigenic contacts of the immune system may mold the immune system more or less in a similar form. This may then, later on in life, translate into a susceptibility to acquire a certain disease or on the other hand into protection to acquire a disease. A second hypothesis is that the gut flora is established in the first weeks of being outside the uterus and it is conceivable that the initial gut microbiota of a baby born in winter may therefore differ from the initial microbiota of a baby born in summer. This may explain why the month of birth could predispose an individual to IBD [3].

This proposed cyclic variation in the birth pattern of patients is called "seasonality" and is not unique for IBD alone. Similar correlations have been documented for other diseases in which the immune system or auto-immunity is a crucial factor in the etiology of the disease such as diabetes type I and asthma [4] [5].

Therefore previous studies have sought a relationship between the month, or season of birth and the risk of developing IBD later in life. However, outcomes of these studies differed substantially [2] [6]-[16]. So far no such study was done in the Netherlands.

Since earlier studies are inconsistent and there is a lack of data from the Netherlands, this study aimed to examine the effect of the month of birth on the probability to develop IBD later in life in a Dutch population. We compared birth data from a large cohort of IBD patients with a control group that consisted of IBS patients from the same geographic region.

\section{Methods}

For this study, data from 4 different hospitals in different geographical areas of the Netherlands were used. These hospitals were: Bernhoven Hospital-Oss, Meander MC-Amersfoort, MC Alkmaar (MCA), and Haga Teaching Hospital-Den Haag (Haga). Gastroenterologists in the Netherlands are all working in specialty groups that are based in a hospital. In the Netherlands there is a uniform registration and billing system for medical diagnosis (Diagnose-Behandel-Combinatie (DBC)). Patients were considered to suffer from IBD when they were entered in the hospital billing system with DBC registration code 601 (CD) or 602 (UC), controls were all patients from the same hospital with DBC code 205 (IBS).

The medical diagnosis as registered in the DBC system is a very reliable source for patient data and epidemiology since we can be sure that a patient with a certain DBC code is indeed being diagnosed with the disease that is registered in the system. There were no other specific inclusion of exclusion criteria; all patients with the right DBC diagnostic code from the 4 hospitals were included. From the patient data in the DBC billing system only the date of birth and the gender of the patient were obtained.

\subsection{Ethics}

In the analysis no patient identifiers were used. According to Dutch law this study did not require approval from an institutional medical Ethic Board because only date of birth and gender of patients were revealed to the investigator.

\subsection{Statistical Analysis}

The rates of births per month in a population are not evenly distributed over the year, for example in 2010 more children in the Netherlands were born in the months July, August, September and October [17]. We therefore need a control group which represents the true distribution of births over the year. Patients with irritable bowel 
syndrome served as a control group in this study. In order to test whether there was heterogeneity (a significant deviation from an expected distribution) between the months and seasons of birth we used the chi-square test.

Birth data from the control group were used to calculate expected rates of births per month. The observed monthly rates of birth during the year in patients with CD and UC respectively were compared to the calculated expected rates.

Secondly, seasonal birth rates were compared. Four clusters of three months were used to define the different seasons: spring (March, April, May), summer (June, July, August), autumn (September, October, November), winter (December, January, February).

The Database with birth dates and genders of the patients was built and managed with Microsoft ${ }^{\circledR}$ Excel software. All statistical analysis was performed using IBM ${ }^{\circledR}$ SPSS $^{\circledR}$ Statistics software, version 18. Differences were considered to be statistical significant with P-values $<0.05$.

\section{Results}

The study population consisted of 2476 IBD patients: 1183 CD patients, $1293 \mathrm{CU}$ patients and a control group of 2113 irritable bowel syndrome patients. Patient numbers and the percentages of CD, UC and IBS patients from the different hospitals are shown in Table 1 . The baseline characteristics were not significantly different between the groups, although patients in the control group were slightly older. Also, CD patients and IBS patients were mostly female whereas this gender distribution was fifty-fifty in UC patients. These data are shown in Table 2.

There was no difference in distribution of months of birth over the year between patients with IBD and the control group. Table 3 and Table 4 show the expected and observed birth rates in every month of the year for 1183 CD patients and 1293 UC patients respectively. P-values are 0.428 and 0.237 . Nor was there any difference when the expected and observed birth rates for the four different seasons of the year are compared between IBD patients and the control group. P-values are 0.311 for CD patients and 0.812 for UC patients. This is shown in Table 5 and Table 6. Based on these data a specific month of birth, or birth in one of the four seasons, is not a risk factor for developing CD or CU later in life.

\section{Discussion}

In this largest study to date we found no role for seasonality in the pathogenesis of IBD. We used birth data obtained from the Dutch billing system for gastroenterologists to investigate the monthly and seasonal variations in month of birth among patients with CD and UC. For this study data were collected from four different hospitals in various regions of Holland. This makes the data representative for the whole country and it reduces the

Table 1. Numbers of patients from four different hospitals.

\begin{tabular}{ccccc}
\hline & Crohn's disease & Ulcerative Colitis & Control Group & Total \\
\hline $\begin{array}{c}\text { Bernhoven } \\
\text { N (\%) }\end{array}$ & $204(25.2)$ & $198(24.5)$ & $406(50.2)$ & $808(100)$ \\
MCA & $255(17.2)$ & $352(23.8)$ & $872(59.0)$ & $1479(100)$ \\
N (\%) & $421(30.9)$ & $408(30.0)$ & $532(39.1)$ & $1361(100)$ \\
Haga & $304(24.3)$ & $342(27.4)$ & $603(48.3)$ & $1249(100)$ \\
$\begin{array}{c}\text { N (\%) } \\
\text { Meander MC } \\
\text { N (\%) }\end{array}$ & & & & \\
\hline
\end{tabular}

Table 2. Baseline characteristics.

\begin{tabular}{|c|c|c|c|c|}
\hline & $\begin{array}{l}\text { Crohn's Disease } \\
\qquad(N=1183)\end{array}$ & $\begin{array}{l}\text { Ulcerative Colitis } \\
(\mathrm{N}=1293)\end{array}$ & $\begin{array}{l}\text { Control Group } \\
(N=2113)\end{array}$ & P-Value \\
\hline Mean age (years) & 46 & 50 & 55 & $\begin{array}{l}\text { Crohn: } 0.18 \\
\text { Colitis: } 0.56\end{array}$ \\
\hline \multicolumn{5}{|l|}{ Sex $(\%)$} \\
\hline Male & $34.2 \%$ & $48.7 \%$ & $31.1 \%$ & Crohn: 0.66 \\
\hline Female & $65.8 \%$ & $51.3 \%$ & $68.9 \%$ & Colitis: 0.90 \\
\hline
\end{tabular}


Table 3. Observed vs. expected rates of birth for every month in 1183 patients with Crohn’s disease.

\begin{tabular}{ccc}
\hline Months of the year & Observed Number & Expected Number \\
\hline January & $98=$ & 109.8 \\
February & $99 \uparrow$ & 88.5 \\
March & $89 \downarrow$ & 109.8 \\
April & $96=$ & 104.1 \\
May & $109=$ & 108.6 \\
June & $99=$ & 94.6 \\
July & $105=$ & 101.9 \\
August & $114=$ & 108.0 \\
September & $108 \uparrow$ & 96.3 \\
October & $92=$ & 93.0 \\
November & $79=$ & 85.1 \\
December & $95 \uparrow$ & 83.4 \\
$\chi^{2}$ (11 d.f.) & 11.184 & \\
P-value & 0.428 & \\
\hline
\end{tabular}

Table 4. Observed vs. expected rates of birth for every month in 1293 patients with ulcerative colitis.

\begin{tabular}{ccc}
\hline Months of the year & Observed Number & Expected Number \\
\hline January & $115=$ & 120.0 \\
February & $90=$ & 96.7 \\
March & $137 \uparrow$ & 120.0 \\
April & $106=$ & 113.8 \\
May & $100 \downarrow$ & 118.7 \\
June & $110=$ & 103.4 \\
July & $125 \uparrow$ & 111.3 \\
August & $100 \downarrow$ & 118.0 \\
September & $104=$ & 105.2 \\
October & $102=$ & 101.6 \\
November & $107 \uparrow$ & 93.0 \\
December & $97=$ & 91.2 \\
$\chi^{2}$ (11 d.f.) & 13.926 & \\
P-value & 0.237 & \\
\hline
\end{tabular}

Table 5. Observed vs. expected rates of birth for every season in 1183 patients with Crohn’s disease.

\begin{tabular}{ccc}
\hline Season & Observed Number & Expected Number \\
\hline Spring & $294 \downarrow$ & 322.5 \\
Summer & $318=$ & 304.5 \\
Autumn & $279=$ & 274.3 \\
Winter & $292=$ & 281.7 \\
$\chi^{2}$ (3 d.f.) & 3.573 & \\
P-value & 0.311 & \\
\hline
\end{tabular}

Table 6. Observed vs. expected rates of birth for every season in 1293 patients with ulcerative colitis.

\begin{tabular}{ccc}
\hline Season & Observed Number & Expected Number \\
\hline Spring & $343=$ & 352.5 \\
Summer & $335=$ & 299.9 \\
Autumn & $313=$ & 307.9 \\
Winter & $302=$ \\
$\chi^{2}$ (3 d.f.) & 0.957 \\
P-value & 0.812 \\
\hline
\end{tabular}


probability of selection bias. Furthermore the unaffected control population was selected from the same hospitals and therefore originated from the same geographical area. Our data show no deviation from an expected distribution in birth rates over the year in IBD patients as compared to a control group of IBS patients. These findings suggest there is no seasonal pattern in the risk to develop either CD or CU in the Netherlands.

Previous studies have had contradictory results. A very large population study from the United Kingdom (UK) found no seasonality in the birth dates of IBD patients, which is in line with our data [12]. A second paper from the UK $(\mathrm{N}=1624)$ found a weak association with being born in the first half of the year and developing Crohn's disease [6]. An older study $(\mathrm{N}=2175)$ from Sweden showed clustering of births from IBD patients during spring. This was more pronounced for CD than for UC [2]. The same outcomes were recently found in a case-control study from Canada $(\mathrm{N}=11145)$. A study from Israel $(\mathrm{N}=844)$ found a significant seasonality in birth dates of CD patients: birth during the winter period was associated with a reduced risk of developing CD and birth in the summer period was associated with an increased risk. No such clustering of births was found in UC patients [9]. A more recent Chinese study $(\mathrm{N}=409)$ showed that the birth rates of UC patients were higher in the autumn-winter period than in the spring-summer period, which is in line with a Korean study $(\mathrm{N}=727)$ that was published lately [13]. Furthermore a study from Belgium $(\mathrm{N}=1025)$ showed only significant results for the month June: individuals born in this month had a reduced risk of developing CD later in life [10]. Three studies investigated the season of birth and childhood IBD [7] [8] [11]. One Danish study showed a peak in birth dates in August and a trough in March, the second one, a British study, didn't found any seasonality effect, and in the last study from Slovakia most children that developed IBD were born between June and October and least were born between December and March [7] [8] [11].

Although, as described above, some previous studies have suggested that a relationship between the month of birth and the likelihood of developing disease later in life does exist these data are inconsistent and contradictory in their findings. If there was true seasonality for IBD patients, one would expect positive studies would all show a similar pattern, and this is not the case. However the summer months in the northern hemisphere are the winter months in the southern hemisphere and there are a lot of different climate zones all over the world. Furthermore none of the studies reflects whether the seasons of the consecutive years that were studied were typical or hotter/colder than normal. These can all be reasons for the inconsistency of the outcomes of the previously conducted studies.

Also, the number of patients in all of these studies differed and the observed effects might have occurred by chance alone. On the other hand when the effect size is small there is a chance of type II errors in studies with small sample sizes. The present study, with 2476 IBD patients (1183 CD patients, 1293 UC patients), investigates one of the largest IBD patient cohorts of all studies yet and its result are therefore probably more robust.

\section{Conclusion}

In summary, the present study shows that babies born in certain months or seasons of the year do not have a higher risk of developing IBD later in life in the cohort. Based on our result we conclude that in the Netherlands seasonality plays no role in the pathogenesis of IBD.

\section{References}

[1] Xavier, R.J. and Podolsky, D.K. (2007) Unravelling the Pathogenesis of Inflammatory Bowel Disease. Nature, 448, 427-434. http://dx.doi.org/10.1038/nature06005

[2] Ekbom, A., Zack, M., Adami, H.O. and Helmick, C. (1991) Is There Clustering of Inflammatory Bowel Disease at Birth? American Journal of Epidemiology, 134, 876-886.

[3] Shaw, S.Y., Blanchard, J.F. and Bernstein, C.N. (2011) Association between the Use of Antibiotics and New Diagnoses of Crohn's Disease and Ulcerative Colitis. American Journal of Epidemiology, 106, 2133-2142. http://dx.doi.org/10.1038/ajg.2011.304

[4] Kahn, H.S., Morgan, T.M., Case, L.D., Dabelea, D., Mayer-Davis, E.J., Lawrence, J.M., Marcovina, S.M. and Imperatore, G. (2009) Search for Diabetes in Youth Study Group. Association of Type 1 Diabetes with Month of Birth among US Youth: The Search for Diabetes in Youth Study. Diabetes Care, 32, 2010-2015. http://dx.doi.org/10.2337/dc09-0891

[5] Gazala, E., Ron-Feldman, V., Alterman, M., Kama, S. and Novack, L. (2006) The Association between Birth Season and Future Development of Childhood Asthma. Pediatric Pulmonology, 41, 1125-1128.

http://dx.doi.org/10.1002/ppul.20442 
[6] Haslam, N., Mayberry, J.F., Hawthorne, A.B., Newcombe, R.G., Holmes, G.K. and Probert, C.S. (2000) Measles, Month of Birth, and Crohn's Disease. Gut, 47, 801-803. http://dx.doi.org/10.1136/gut.47.6.801

[7] Sørensen, H.T., Pedersen, L., Nørgård, B., Fonager, K. and Rothman, K.J. (2001) Does Month of Birth Affect Risk of Crohn's Disease in Childhood and Adolescence? British Medical Journal, 323, 907. http://dx.doi.org/10.1136/bmj.323.7318.907

[8] Card, T.R., Sawczenko, A., Sandhu, B.K. and Logan, R.F. (2002) No Seasonality in Month of Birth of Inflammatory Bowel Disease Cases: A Prospective Population Based Study of British under 20 Year Olds. Gut, 51, 814-815. http://dx.doi.org/10.1136/gut.51.6.814

[9] Chowers, Y., Odes, S., Bujanover, Y., Eliakim, R., Bar Meir, S. and Avidan, B. (2004) The Month of Birth Is Linked to the Risk of Crohn's Disease in the Israeli Population. American Journal of Gastroenterology, 99, 1974-1976. http://dx.doi.org/10.1111/j.1572-0241.2004.40058.x

[10] Van Ranst, M., Joossens, M., Joossens, S., Van Steen, K., Pierik, M., Vermeire, S. and Rutgeerts, P. (2005) Crohn’s Disease and Month of Birth. Inflammatory Bowel Disease, 11, 597-599. http://dx.doi.org/10.1097/01.MIB.0000163697.34592.d4

[11] Mikulecký, M. and Cierna, I. (2005) Seasonality of Births and Childhood Inflammatory Bowel Disease. Wiener klinische Wochenschrift, 117, 554-557. http://dx.doi.org/10.1007/s00508-005-0391-2

[12] Sonnenberg, A. (2009) Date of Birth in the Occurrence of Inflammatory Bowel Disease. Inflammatory Bowel Disease, 15, 206-211. http://dx.doi.org/10.1002/ibd.20730

[13] Bai, A., Guo, Y., Shen, Y., Xie, Y., Zhu, X. and Lu, N. (2009) Seasonality in Flares and Months of Births of Patients with Ulcerative Colitis in a Chinese Population. Digestive Diseases and Sciences, 54, 1094-1098. http://dx.doi.org/10.1007/s10620-008-0453-1

[14] Angelucci, E., Cocco, A., Cesarini, M., Crudeli, A., Necozione, S., Caprilli, R. and Latella, G. (2009) Monthly and Seasonal Birth Patterns and the Occurrence of Crohn's Disease. American Journal of Gastroenterology, 104, 1608-1609. http://dx.doi.org/10.1038/ajg.2009.107

[15] Shaw, S.Y., Nugent, Z., Targownik, L.E., Singh, H., Blanchard, J.F. and Bernstein, C.N. (2014) Association between Spring Season of Birth and Crohn's Disease. Clinical Gastroenterology and Hepatology, 12, 277-282. http://dx.doi.org/10.1016/j.cgh.2013.07.028

[16] Jung, Y.S., Song, C.S., Kim, E.R., Park, D.I., Kim, Y.H., Cha, J.M., Kim, J.H., Lee, S.H., Eun, C.S. and Han, D.S. (2013) Seasonal Variation in Months of Birth and Symptom Flares in Korean Patients with Inflammatory Bowel Disease. Gut Liver, 7, 661-667.

[17] Statline, Centraal bureau voor de statistiek. Bevolking en bevolkingsontwikkeling; per maand, kwartaal en jaar. http://statline.cbs.nl/StatWeb/publication/?DM=SLNL\&PA=37943NED\&D1=10-20\&D2=255-257,259-261,263-265,2 $67-269 \& \mathrm{VW}=\mathrm{T}$ 